\title{
Determinación de la obligación tributaria: el problema de la transversalidad de la determinación de la obligación en las relaciones juridicas públicas y privadas
}

Determination of the Tax Obligation: the
Problem of the Transverse Feature of the
Determination of the Obligation in the
Public and Private Legal Relationships

Jorge Antonio Lay Lozano*

http://dx.doi.org/10.21503/lex.v14i18.1244

* Doctor en derecho por la Universidad Alas Peruanas. Magíster en derecho con mención en aduanas por la Universidad Alas Peruanas. Abogado por la Universidad de San Martín de Porres. Bachiller en administración de empresas por la Universidad Ricardo Palma. Catedrático de la Universidad de San Martin de Porres. Profesor de pregrado y postgrado de la Universidad Alas Peruanas. Abogado oficializado para ejercer como juez superior en la Corte Superior de Lima Este. Ex-Defensor Público asignado a la Primera Sala Penal Especial Anticorrupción. Email: consultalegal_27@hotmail.com,j_lay@doc. uap.edu.pe

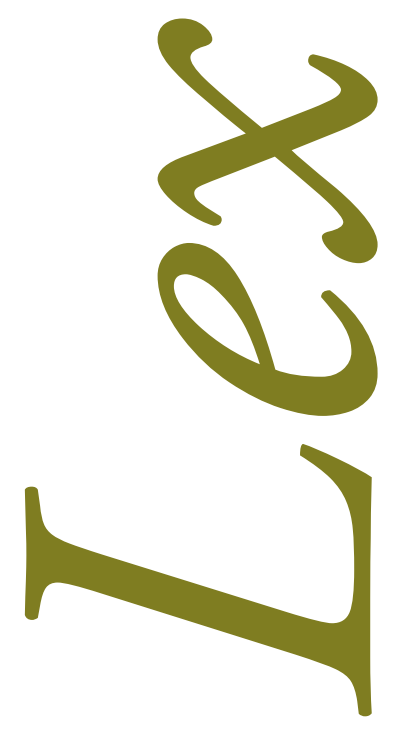




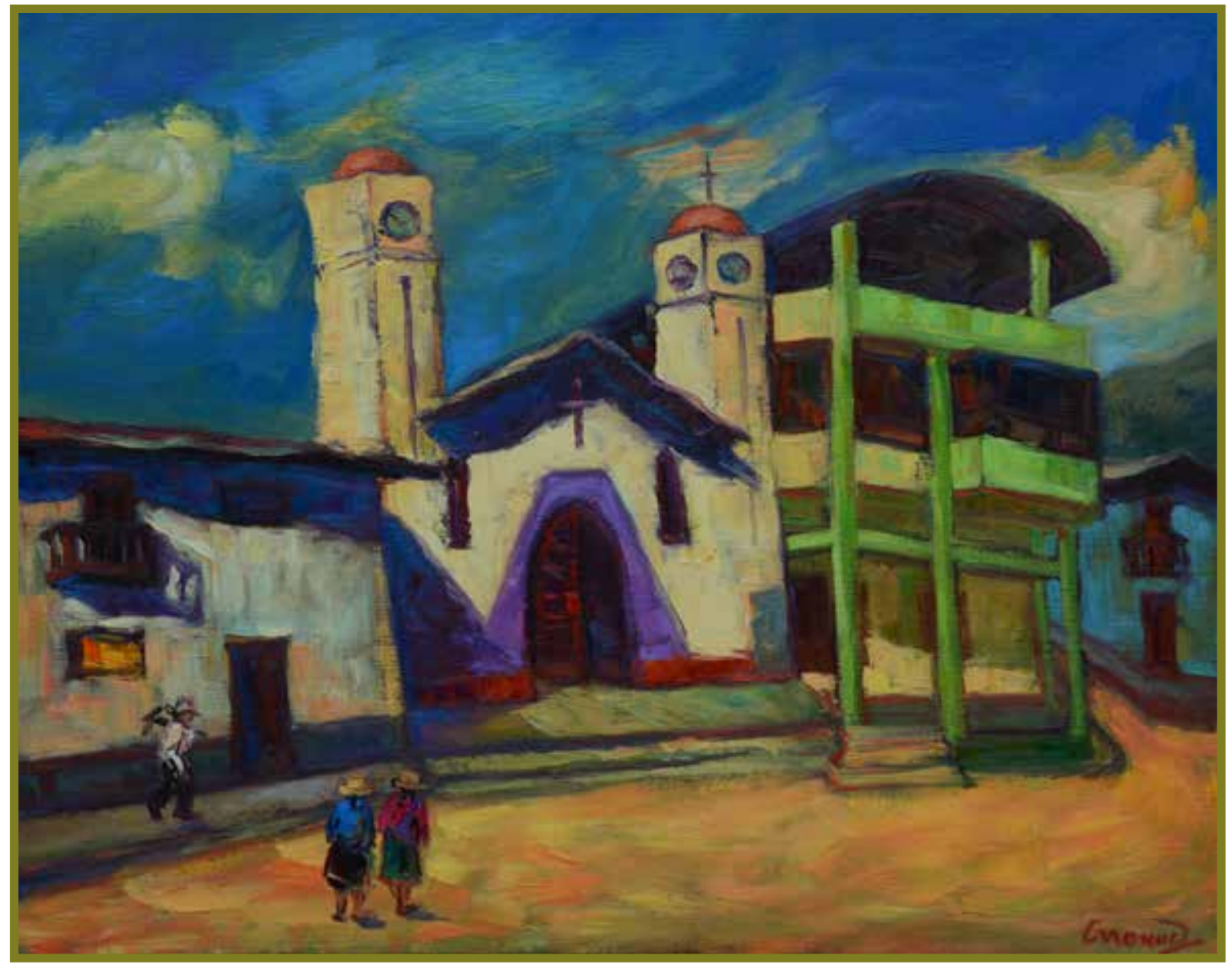

Iglesia de Bolívar. Óleo sobre lienzo $(54 \mathrm{~cm}$ x $73 \mathrm{~cm})$. Ever Arrascue. 


\section{RESUMEN}

Las relaciones conflictuales se inician con la incertidumbre de las prestaciones que hay que cumplir. En tal sentido, delimitar el importe o quantum de dicha obligación no solo es una necesidad en el derecho, sino que su eficacia crea certeza en cada uno de los sujetos de derecho hacia el alcance de dicho límite, para que en el futuro no se imponga la ambigüedad, la falta de exigibilidad y los actos de confusión que agudizan el caos y los márgenes de conflicto. Por ello, no bastan las normas abstractas para destacar ciertas exigencias que aun materializadas en la ley continúan siendo imprecisas; hay que delimitar la prestación, pues con ello se logra confianza, predictibilidad y seguridad en el cumplimento de las obligaciones.

Palabras clave: tributación, ley tributaria, relaciones jurídicas públicas y privadas.

\section{ABSTRACT}

The conflictive relations begin with the uncertainty of the obligation to be complied. In that sense, limiting the amount or quantum of that obligation is not only a need in law, but its effectiveness creates certainty in each of the subjects of law to the extent of that limit, so that ambiguity is not imposed in the future, nor the lack of enforceability and the acts of confusion that exacerbate the chaos and conflict margins. Therefore, abstract provisions are not enough to highlight certain requirements that even embodied in the law remain vague; we must define the obligation because it provides confidence, predictability and security in the fulfillment of obligations.

Key words: taxation, tax law, public and private legal relationships. 
Si nada es evidente de por si, nada es comprobable, y si nada es obligatorio por si mismo, nada es obligatorio en absoluto.

Cuive Staples Lewis (1898-1963), escritor británico.

\section{INTRODUCCIÓN}

El tema que suscita este artículo es la determinación de la obligación tributaria, entendiéndose este procedimiento de uno que se deriva de una actividad impositiva, en la cual el Estado, en virtud de su poder de imposición, exige una carga fiscal al que corresponde entregar dinero al fisco en cuanto ha ocurrido el hecho previsto en la ley como generador de dicha obligación: Está por demás establecer que estamos en la esfera del derecho público; sin embargo, el problema de la determinación de la obligación que se tramita sin mayores contratiempos en la vía del derecho público también se presenta, y con frecuencia, en la esfera privada

El tema interesa no solo en el ámbito tributario —entiéndase este como una rama del derecho y particularmente vinculado al derecho financiero, en el sentido de que su contenido, objeto y aplicación en el orden fiscal resulta pertinente a fin de entender la verdadera dimensión de su exigencia-, sino que por su carácter transversal es aplicable a la propia ciencia jurídica, instalándose en el derecho de las obligaciones del derecho civil, pero con un radio de expansión mucho mayor, lo que ha incitado la presentación del artículo en comento.

Como bien se ha establecido, el objeto de la ciencia jurídica en general y del derecho en particular es la solución de conflictos con relevancia jurídica. A través de la observación y análisis, prefija qué conductas van a ser relevantes para el derecho y cuáles no; en este último caso, las aleja del campo de estudio; la determinación de la obligación tributaria tiene una implicancia plurifásica, ya que gracias a este procedimiento se establece sin lugar a dudas el quantum de lo que hay que cumplir, logrando con ello la validez de lo exigible y la satisfacción 
de un sujeto de derecho público o privado. En este caso en particular, el esbozo del estudio de la determinación de la obligación tributaria la vamos a fijar en lo público, pero finalmente, como se indica en los párrafos ingresantes, su interpretación, análisis y aplicación va a ser útil en otras ramas del derecho, como ya se explicó.

El estatus de la determinación de la obligación tributaria, que establece el Código Tributario, es ciertamente mucho más eficaz que la que se maneja aplicativamente en el Código Civil, ya que este desarrolla las obligaciones de dar, hacer y no hacer, sin una previa conceptualización de la misma, dejando esta labor a la doctrina que complementa el vacío legislativo del citado código, incluyendo las teorías sobre la obligación en el ámbito privado que vale la pena estudiar a fin de lograr una aprehensión de la misma.

Teniendo en cuenta que el derecho tiene como objeto las relaciones jurídicas públicas y privadas, donde el elemento central son las obligaciones que surgen de dichas relaciones, es necesario puntualizar que el objetivo es controlar el alcance de dicha obligación, ya que de otro modo la podríamos sacrificar a su incertidumbre y muy posible descontrol; esto conlleva a que en algún momento y dentro de los propios plazos y condiciones fijados tanto para el ámbito privado y púbico fijemos esta condición a fin de imputar en mora al deudor y de esta manera exigir el cumplimiento de la misma, sin que este pueda cuestionar la validez de la misma a través de la inexigibilidad.

El artículo que presento a continuación va a recorrer la ruta del derecho público y privado a fin de dar a conocer al lector interesado en el conocimiento científico que el centro de atención del derecho surge de la coercibilidad y la coacción y que solo podríamos arribar a dichas instancias cuando se haya delimitado con certeza el quantum de lo que hay que prestar.

\section{EL DERECHO DE LAS OBLIGACIONES: EL PROBLEMA DE LA DETERMINACIÓN}

Dentro del marco jurídico, el concepto de obligación está muy relacionado con el derecho privado, específicamente el derecho civil. Muchos tratadistas han definido a "la obligación", obteniendo una serie de elementos comunes dentro de todas las concepciones doctrinarias. Sin embargo, posteriormente, la obligación se comenzó a utilizar también dentro del derecho público, llevando al nacimiento de la "obligación tributaria". En esta configuración, tal definición no es del todo cierta, ya que, si bien en el ámbito civil ius privatista se advierte el control y manejo de las obligaciones, su manejo conceptual es bastante displicente respecto a la definición que esgrime el propio Código Tributario, de ahí que subsiste la necesidad de que la definición propia de la obligación haya sido arreglada a la doctrina, la que pretende complementar dichos conceptos. 
El derecho de las obligaciones desde la óptica del derecho civil, establecidas en el Libro VI, no aporta conceptualmente sobre el contenido y sobre su trascendencia en la determinación de la obligación; refiere dicho cuerpo de leyes una cuestión aplicativa más que conceptual; sin embargo, habría que atribuir a la norma tributaria, que es la que desarrolla conceptualmente el tema de la obligación en general y la obligación tributaria en particular, partiendo singularmente de la propia determinación de dicha obligación; es así que encontramos que el artículo 1 del Código Tributario emitido mediante el Decreto Supremo No 133-2013-EF es el que define conceptualmente el concepto de la obligación tributaria, estableciéndola desde la idea de relación jurídica muy propia del derecho.

Sin embargo, no todo es gris en el vacío normativo del concepto de la obligación, ya que esta ha sido complementada por la doctrina. Como lo indican los maestros Osterling y Castillo, "constituye una relación jurídica que liga a dos o más personas, en virtud de la cual una de ellas, llamada deudor, debe cumplir una prestación a favor de la otra, llamada acreedor, para satisfacer un interés de este último digno de protección". ${ }^{1}$

Hay que tener en consideración que dentro del sistema jurídico, y más directamente en el ordenamiento jurídico, el objeto y contenido del derecho es la regulación de situaciones y relaciones jurídicas existentes; en esa misma línea de argumentación, la obligación debe entenderse como un vínculo que obliga a alguien a efectuar una determinada prestación pecuniaria a favor de otro sujeto de derecho o incluso frente a un tercero no vinculado por dicha relación jurídica, sino por un factor de conexión.

De igual forma, el artículo $2^{\circ}$ del Código Tributario, siguiendo la línea de reproducción legislativa de sus predecesores cuerpos normativos, establece el concepto de nacimiento de la obligación tributaria; esto es relevante desde la óptica del derecho público, pero entiéndase que dicha relevancia podría interpretarse y aplicarse, como ya se indicó, en el ámbito privado.

Claro está que si definimos el tema de la determinación de la obligación tributaria en el ámbito público, la respuesta directa es el elemento consustancial en dicha relación jurídico pública, la misma que no puede ser otra que la propia norma, ello, en referencia al elemento consustancial a las relaciones privadas, donde el elemento relevante y consustancial es la manifestación de la voluntad, en virtud de la propia autonomía de los sujetos pertenecientes al orden privado y que se consagra con el consentimiento, ello en referencia al artículo 140 del Código Civil sobre "acto jurídico".

1 Felipe Osterling Parodi y Mario Castillo Freyre, Tratado de las obligaciones, vol. XVI, tomo 1 (Lima: Pontifica Universidad Católica del Perú, 1994). 


\section{LA DETERMINACIÓN DE LA OBLIGACIÓN EN LAS OBLIGACIONES ALIMENTARIAS: UNA VISIÓN RETROSPECTIVA AL DERECHO ALIMENTARIO}

En el derecho alimentario también se observan deficiencias normativas que inducen a generar desazón en los propios tribunales nacionales sobre la interpretación y aplicación de las normas referentes a aspectos conducentes en el derecho.

Los alimentos, como lo define el propio Código Civil en su artículo 472, son todos aquellos indispensables para el sustento, habitación, vestido, educación entre otros que requiera una persona sujeto de derechos denominada alimentista, esto en virtud del lazo consanguíneo o de otra naturaleza "cónyuges" que establece que dicha relación debe ser satisfecha por parte de la persona llamada a cumplirla.

La obligación alimentaria como tal entonces se encuentra delimitada bajo el concepto del interés superior del niño, y excepcionalmente se extiende hacia los mayores incapaces, como lo dispone el artículo 483 del Código Civil, es decir, cuando la persona mayor edad no se encuentre en aptitud de atender a su subsidencia por causas de incapacidad física o mental $(\ldots) .^{2}$

Por otro lado, una de las principales características del derecho alimentario es su gran variabilidad, es decir, estas se pueden reajustar de acuerdo a la disminución de ingresos del que debe prestarlas y/o si disminuyen las causales de necesidad originarias por parte del propio alimentista; ello está previsto en el ordenamiento sustantivo cuando nos referimos a los casos de disminución o aumento de la carga alimenticia.

A nivel del procedimiento, esto se materializa a través de lo que se conoce con aumento, prorrateo, reducción o exoneración de la pensión alimenticia, la misma que desarrolla la norma sustantiva civil en sus artículos 482 y 483.

\section{SOBRE EL PROBLEMA DE LA INCORPORACIÓN DEL ARTÍCULO 565-A EN EL CÓDIGO CIVIL PERUANO}

Lo desarrollado no deja de pertenecer a un derecho debidamente justificado por razones de consanguinidad o afinidad "cónyuges" y se presenta de forma uniforme en nuestro sistema jurídico, fundamentalmente de influencia germano-románica, eurocontinental, básicamente normativo, como en otros ordenamientos jurídicos equivalentes; sin embargo, el tema

2 Código Civil. Artículo 483: El obligado a prestar alimentos puede pedir que se le exonere si disminuyen sus ingresos, de modo que no pueda atenderla sin poner en peligro su propia subsistencia, o si ha desaparecido en el alimentista el estado de necesidad. Tratándose de hijos menores, a quienes el padre o la madre estuviese pasando una pensión alimenticia por resolución judicial, esta deja de regir al llegar aquellos a la mayoría de edad. Sin embargo, si subsiste el estado de necesidad por causas de incapacidad física o mental debidamente comprobadas o el alimentista está siguiendo una profesión u oficio exitosamente, puede pedir que la obligación continúe vigente. 
presenta una seria disfuncionalidad respecto a la posibilidad de que mediante un proceso se alcance el objeto de referencia en cuanto a modificar la obligación alimentaria, bajo la forma de reducción, prorrateo o exoneración de las pensiones alimenticias.

En el mes de diciembre del año 2009, entró en vigencia la Ley $\mathrm{N}^{\circ} 29486$, la misma que modifico el Código Procesal Civil, incorporando el artículo 565-A, el mismo que incorpora como un requisito especial para la admisión de la demanda de reducción, variación, prorrateo o exoneración de la pensión alimenticia, que el demandante obligado a la prestación de alimentos acredite encontrarse al día en el pago de la pensión alimenticia.

Como lo refiere el profesor Marco Antonio Celis Vásquez, sobre un artículo de la validez constitucional de la norma, aspectos sobre el que no pretendemos incidir, se cuestiona significativamente que esta norma que modificó el Código Civil sea de carácter inconstitucional, ya que atentaría con el derecho a la tutela judicial efectiva que se encuentra establecida en el artículo 4 del Código Procesal Constitucional y en la propia Constitución, consagrado en su inciso $3^{\circ}$ del artículo 139, entendiéndose a la tutela judicial como "aquella situación jurídica de una persona en la que se respeten, de modo enunciativo, sus derechos de libre a acceso al órgano jurisdiccional, a probar, de defensa, al contradictorio e igualdad sustancial en el proceso, a no ser desviado de la jurisdicción predeterminada ni sometido a procedimientos distintos de los previstos por la ley, a la obtención de una resolución fundada en derecho, a acceder a los medios impugnatorios regulados, a la imposibilidad de revivir procesos fenecidos, a la actuación adecuada y temporalmente oportuna de las resoluciones judiciales y a la observancia del principio de legalidad"; entiéndase que dicho derecho a la tutela judicial garantiza al justiciable ante su pedido de tutela, el deber del órgano jurisdiccional de observar el debido proceso y de impartir justicia dentro de los estándares mínimos establecidos por los instrumentos internacionales.

En consecuencia, el debido proceso parte de la concepción del derecho de toda persona a la tutela jurisdiccional efectiva, y se concreta a través de las garantías que, dentro de un iter procesal diseñado en la ley, están previstas en la Constitución Política del Perú.

En todo caso, esta incorporación de la norma en comentario a la norma sustantiva del Código Civil vinculada directamente con el derecho de familia y más propiamente dicha con el derecho alimentario, ha causado no pocas complicaciones a los operadores de justicia, ya que en algunos casos se ha pretendido componer la interpretación y aplicación de esta modificatoria en los fallos al momento de admitir la demanda; otro criterio son los plenos jurisdiccionales, creados principalmente en los niveles básicos de la administración de justicia, con el objeto de uniformizar los criterios de los jueces al momento de aplicar o interpretar adecuadamente esta comentada modificatoria, lo que ha causado serios aprietos a los jueces de la república competentes para conocer estos casos, incluso muchos de ellos han 
tenido que resolver este conflicto aplicando adecuadamente el control difuso, procedimiento incuestionable en un Estado constitucional de derecho.

Pero al margen del contenido constitucional de la norma, en esta sección lo que pretendemos es hacer un esfuerzo para explicar que más allá del cuestionamiento de la validez constitucional de la norma, que al fin y al cabo podría declararse a través de un proceso de inconstitucionalidad, establecido en el numeral 4 del artículo 200 de la Constitución Política "Acción de Inconstitucionalidad" que recae contra normas con rango de ley; lo que pretendemos es establecer y diseñar el mecanismo del derecho de las obligaciones para tal fin. ${ }^{3}$

Como se establece en párrafos anteriores, subsiste el tema de la obligación a fin de que sea eficaz en estos casos en concreto, ya que el requisito de admisibilidad para su interferencia a fin de que esta sea declarada, se encuentra en establecer que efectivamente el demandante en estos nuevos procesos, "reducción, variación, prorrateo o exoneración", se encuentre al día en las pensiones fijadas. Pero esta exigencia linda en establecer si existe deuda pendiente que afecte el acceso a la tutela judicial, y ciertamente en los procesos de alimentos por su gran variabilidad, "pagos parciales, pagos fuera del periodo, liquidaciones parciales, liquidaciones en trámite, solicitud de prescripción de la pensiones alimenticia, reducción, prorrateo, o exoneración por otros periodos, e incluso devoluciones ordenadas a favor el demandado por pago en exceso", en consecuencia, dicha premisa de acreditar encontrarse al día en el pago de la pensión alimenticia no pasa de ser una metáfora, ya que bajo dicho supuesto bastaría que el propio accionante declare estar al día para que se califique positivamente su demanda y se admita la misma.

Es por ello que el requisito de admisibilidad carece de sustento en el tiempo, ya que las condiciones originarias de la obligación alimentaria, a través de una sentencia firme o de una conciliación extrajudicial o judicial con el mismo valor de sentencia, pueden variar a pesar de que lo fijado en una pensión alimenticia por un monto fijo o en relación de un porcentaje asignado (normalmente mensual), al momento dinámico de la presentación de otra acción conexa con dicha obligación ya definida; en este último caso, nos encontramos con el problema del quantum de dicha obligación, es decir, a cuánto asciende el monto de la deuda alimentaria a fin de cumplir con el requisito establecido en la modificatoria materia de comentario; para ello, ya no resulta idóneo el conocer la pensión fija ni el porcentaje, sino que se requiere una actuación probatoria incidental a fin de realizar un análisis de cumplimiento, y a partir de ello acreditar que el demandante en este nuevo proceso se encuentra en condiciones de accionar o si en virtud de esta ley se encuentra impedido de ello, debiéndose declarar la inadmisibilidad de su pedido al no satisfacer el requisito de forma, y posteriormente su destino sería la improcedencia de su pedido.

3 Marco Celis, “La inconstitucionalidad de la Ley 29486” (artículo jurídico, 2011). 
El problema subsiste y consideramos que dicha norma carece de sustento técnico legal, al pretender resolver el cumplimiento de la obligación alimentaria, a través de una restricción; y aquí también tiene plena validez el concepto de la obligación que pretendemos desarrollar en este artículo, ya que solo a través de un procedimiento como el de la determinación de la obligación se lograría finalmente el propósito de la ley.

El mecanismo de corrección jurídica no colisiona con el sustento de la obligación que necesariamente tiene que desarrollarse a través de determinar el quantum de dicha obligación y no solo detenerse en ello, sino continuar a fin de verificar si esta se encuentra en un estado de exigibilidad; por lo que el mecanismo del procedimiento de determinación de la obligación es útil y necesario a fin de imputar en mora al deudor alimentario.

En cuanto a la determinación de la obligación alimentaria, deben recogerse los mismos métodos que se aplican al derecho público fiscal, que como ya se indicó es la rama jurídica que mejor ha desarrollado conceptualmente la obligación, justamente en la obligación tributaria del artículo 1 del Código Tributario, como ya se menciona anteriormente, obviamente con las disquisiciones del caso, al pertenecer este al derecho civil, es decir, determinar la obligación alimentaria a la fecha de la presentación de la demanda a fin de cumplir con el requisito de admisibilidad ya comentado; para ello, la determinación de la obligación parte de una deuda exigible en el tiempo, la misma que solo es posible mediante la aprobación de dichas pensiones devengadas, previo a los mecanismos del propio proceso y a la actuación del equipo técnico pericial, con las oposiciones u observaciones de las partes en conflicto, es decir, con el respeto al debido proceso y al derecho a la defensa. ${ }^{4}$

\section{LA OBLIGACIÓN TRIBUTARIA}

El Código Tributario prescribe "la obligación tributaria, que es de derecho público, el vínculo entre el acreedor y el deudor tributario establecido por ley, que tiene por objeto el cumplimiento de la prestación tributaria, siendo exigible coactivamente”.

Villegas denomina a la obligación tributaria como "una relación jurídica principal, indicando a continuación, que es el vínculo jurídico obligacional que se entabla entre el fisco, como sujeto activo que pretende el cobro de un tributo, y un sujeto pasivo que está obligado a su pago". 5

Contrariamente a lo señalado por el doctor Bravo cuando señala que no hay concepto propio de obligación tributaria, debiendo recurrirse a las construcciones del derecho general,

4 Código Civil Peruano (2009). Artículo 565-A: "Requisito para la admisión de la demanda de reducción, variación, prorrateo o exoneración de pensión alimentaria que el demandante obligado a la prestación de alimentos acredite encontrarse al día en el pago de la pensión alimentaria”.

5 Héctor Villegas, Curso de finanzas, derecho financiero y tributario (Buenos Aires: Astrea, 2002). 
sobre todo el privado, y en particular, a la teoría general de las obligaciones, no me queda más que reiterar que es en el derecho tributario donde se diseña el concepto de la "obligación", usando en ese caso la definición de la obligación tributaria establecida en el artículo 1 del Código Tributario, que muy bien hace referencia a tal concepto. ${ }^{6}$

El doctor Huamani en la elaboración del Código Tributario comentado manifiesta sobre la determinación de la obligación tributaria que una vez materializada en la realidad la hipótesis de incidencia tributaria, es decir, ocurrido el hecho previsto en la ley como generador de dicha obligación, nace la obligación tributaria, en virtud del artículo 2 del Código Tributario, pero el nivel de exigibilidad emana directamente del artículo 3 del citado Código Tributario; entonces tenemos en estos tres primeros artículos del Código Tributario: i) el concepto de obligación tributaria, ii) el nacimiento de la obligación tributaria y iii) finalmente la exigibilidad de dicha obligación. A raíz de lo expuesto, podemos afirmar que la obligación tributaria y su propia exigibilidad no parten sino en diferentes momentos por mandato expreso de la ley, lo que implica recurrir al concepto del nacimiento de la obligación tributaria a que hace alusión el artículo 2 del propio Código Tributario, ya que es este el punto de partida para llegar a la exigibilidad de dicha obligación, que, por cierto, en esas instancias ya debe estar plenamente determinada. ${ }^{7}$

Como manifiesta el distinguido maestro Soler, no existe ninguna obligación tributaria que no nazca de la realización de un hecho imponible. ${ }^{8}$

Lo propio detalla Sainz de Bujanda advirtiendo que el proceso generador de la obligación tributaria coincide plenamente con el de la obligación ex lege, e indica: "realizado el supuesto previsto en la norma, se produce el efecto jurídico, sin intervención de la voluntad humana.?

Giuliani, al citar a otros autores, hace referencia a la obligación tributaria como "vínculo obligacional en virtud del cual el Estado tiene el derecho de exigir la prestación jurídica llamada impuesto, cuyo origen radica en la realización del presupuesto de hecho previsto por la ley, de modo tal que esta vendría a constituir el soplo vital de esa obligación de dar que es la obligación". 10

Jarach señala que la "obligación tributaria en general, desde el punto de vista jurídico, es una relación jurídica ex lege, en virtud de la cual una persona (sujeto pasivo principal,

\footnotetext{
Jorge Bravo Cucci, Fundamentos de derecho tributario (Lima: Palestra Editores, 2003).

Concepto de la obligación tributaria: artículo 1 del Código Tributario: "La obligación tributaria, que es de derecho público, es el vínculo entre el acreedor y el deudor tributario, establecido por la ley, que tiene por objeto el cumplimiento de la prestación tributaria siendo exigible coactivamente".

8 Osvaldo Soler, Derecho tributario (Buenos Aires: La Ley, 2002).

9 Fernando Sainz de Bujanda, Lecciones de derecho financiero (Madrid: Universidad Complutense, Facultad de Derecho, 1993).

10 Carlos Giuliani Fonrouge, Derecho financiero, tomo I (Buenos Aires: Ediciones Depalma, 2001).
} 
contribuyente o responsable, está obligado hacia el Estado u otra entidad pública, al pago de una suma de dinero, en cuanto se verifique el presupuesto de hecho determinado por la ley". ${ }^{11}$

En este sentido, existen ciertos elementos que tienen conexión a fin de que se consagre la obligación tributaria. En este caso, lo exigible sustantivamente para tal exigencia "exigir el tributo" constituye un aspecto esencial que se haya configurado un hecho como generador posible de obligaciones tributarias; si no existe una hipótesis legal condicionada "hipótesis de incidencia” no tendríamos aptitud para valorar si el supuesto hecho tendría la condición de imponible, descartando la tesis del hecho generador.

Expuesta esta sección, podemos afirmar que el supuesto de hecho está dentro del parámetro de lo legal, y a partir de dicha premisa establecer la obligación tributaria con la eficacia jurídica pública que ello pueda conllevar.

Por otro lado, no bastaría la afirmación de la existencia de la obligación tributaria, al haber superado el test de hipótesis legal y supuesto de hecho para definir el tema de la obligación tributaria, ya que si bien esta tiene una particular forma en su existencia, no puede ser delimitada o cuantificada, es decir, establecer el quantum de dicha obligación, sin invocar un procedimiento "la declaración" y su contendido la "determinación de la obligación tributaria".

\section{LA OBLIGACIÓN TRIBUTARIA: CONEXIÓN CON LA HIPÓTESIS DE INCIDENCIA TRIBUTARIA}

En general, Ataliba afirma que el derecho tiene como fin resolver conflictos con relevancia que surgen en las relaciones o situaciones jurídicas entre los particulares o entre estos y el Estado; en esa configuración de relaciones de las más complejas, no resulta propio hablar de la obligación tributaria sin reconocer su contenido esencial, y este no puede ser otro que contraernos a cuestionar la validez o invalidez de dichas obligaciones, las que de otro modo no tendrían el sustento ni el respaldo necesario, sin el concepto de hipótesis de incidencia tributaria o hipótesis legal condicionada, tan magistralmente planteada por el profesor brasileño. $^{12}$

Si partimos de la premisa de que el elemento esencial del derecho tributario es la norma, es necesario hacer un recurrido corto pero enriquecedor acerca del concepto de hipótesis de incidencia, para luego resaltar su importancia dentro de la obligación tributaria.

Como indica el maestro brasileño Ataliba, la hipótesis de incidencia es primeramente la descripción legal de un hecho; es la formulación hipotética, previa y genérica, contenida en la ley, de un hecho. Por eso es mera "previsión legal".

11 Dino Jarach, Finanzas públicas y derecho tributario. Estudios de derecho tributario (Buenos Aires: Cima, 1996).

12 Geraldo Ataliba, Hipótesis de incidencia tributaria (Lima: Instituto Peruano de Derecho Tributario, 1987). 
Es, por tanto, mero concepto, necesariamente abstracto. Es formulado por el legislador haciendo abstracción absoluta de cualquier hecho concreto; de ahí la necesidad y responsabilidad de dicho legislador para que dicha abstracción, es decir, la imposición de cargas recaiga efectivamente en los quehaceres económicos que realmente tengan validez fiscal. Pero la "hipótesis legal" no solo es una definición contenida en una ley, sino que pertenece al mundo de los valores jurídicos. Por el contrario, el hecho imponible de donde emerge la obligación tributaria es la realización de esa hipótesis legal y por lo tanto pertenece al mundo de la realidad fáctica.

Pero el concepto de hipótesis de incidencia trabajada con acierto en la escuela tributaria brasileña no es mero y simple concepto, ya que, por definición, es una manifestación legislativa, y está contenida en un enunciado legal. No es un mero concepto, sino un concepto legal, esto es que consta en la ley, consistente de una proposición legislativa. ${ }^{13}$

El tributarista español Pérez de Ayala, en relación a la conexión entre la hipótesis de incidencia y la obligación tributaria, escribe sobre los "momentos" necesarios para que exista una obligación tributaria: la definición por una ley de ciertos supuestos de hecho a cuya hipotética y posible realización la ley atribuye determinados efectos jurídicos (obligación de pagar el tributo), convirtiéndose así en una clase de hechos jurídicos (hecho imponible). La realización de ese hecho jurídico, el hecho imponible, es la que origina la obligación de pagar el tributo.

Este autor distingue bien la creación del tributo, abstractamente, por la ley, y el surgimiento de cada obligación tributaria: fase de creación del tributo (función tributaria abstracta), promulgación de una ley y creación del impuesto como instituto jurídico (definición legal del hecho imponible).

Esta fase se descompone, conceptualmente, en dos momentos:

a) La promulgación de una ley tributaria y la definición, en ella, de una hipótesis legal.

b) La ley vincula la producción de ciertos efectos jurídicos (la obligación de pagar un tributo) a la realización de la hipótesis legal que en ella se contiene, vale decir, al hecho imponible.

Fase de aplicación del tributo (función tributaria concreta): nacimiento de la obligación de contribuir, por haberse realizado el hecho imponible. ${ }^{14}$

13 Geraldo Ataliba, Hipótesis de incidencia tributaria..., 67.

14 José Pérez de Ayala, "La subjetividad tributaria", en Tratado de derecho tributario, tomo segundo (Bogotá: Temis, 2001). 
En el derecho público tributario está vigente el concepto de hipótesis de incidencia tributaria, aporte del maestro brasileño Geraldo Ataliba, quien señala que "hipótesis de incidencia tributaria es la hipótesis de la ley tributaria. Es la conceptualización (concepto legal) de un hecho". ${ }^{15}$

\section{UNIVERSALIDAD DEL CONCEPTO DE HIPÓTESIS DE INCIDENCIA}

El concepto de hipótesis de incidencia es universal, en el sentido de que no deriva de la observación de un sistema particular, ni se compromete con ningún instituto jurídico localizado en tiempo y espacio.

Es aplicable tanto al derecho vigente, como al derogado o al que se está constituyendo. Es válido, aquí, como allá, donde exista derecho, porque es un concepto lógico jurídico; pero su extensión abarca definitivamente no solo a la posibilidad de que ocurra el supuesto "hecho", sino que identifica a este hecho con su categoría de jurídico y comprende necesariamente a la obligación tributaria. Es este el vínculo del nacimiento de la obligación tributaria, que ya no trascurre en el mundo de lo abstracto, sino que deriva en un efecto terminal en la obligación tributaria.

\section{LA OBLIGACIÓN TRIBUTARIA: NECESIDAD DE LA DETERMINACIÓN}

Lo que aparece del propio Código Tributario atribuye el facilismo de señalar que la obligación tributaria nace cuando se presenta el supuesto previsto en la ley como generado de dicha obligación; es decir, se habría cumplido el aspecto fáctico de la hipótesis legal condicionada, y a partir de ello estamos ante un hecho incidido, identificado por muchos autores como el hecho imponible o acto generador.

Como lo expone dilectamente el licenciado Sergio Francisco de la Garza, de la Universidad de Nuevo León, tomando algunos conceptos de Sainz de Bujanda, las obligaciones, en general, pueden tener tres fuentes:

a) La ley, por sí misma, sin conexión con ningún hecho jurídico: a las obligaciones que nacieran de esta forma se les atribuye el nombre de obligaciones meramente legales.

b) La ley unida a la realización de un hecho generador, previsto por ella y distinto a la voluntad de obligarse: a estas obligaciones se les llama obligaciones legales u obligaciones ex lege.

c) La voluntad de un sujeto, dirigida a producir a su cargo el nacimiento de una obligación, esto es, a convertirse en obligado, y reconocida por la ley como fuente de dicha obligación: obligaciones voluntarias. ${ }^{16}$

15 Geraldo Ataliba, Hipótesis de incidencia tributaria..., 67.

16 Fernando Sainz de Bujanda, Lecciones de derecho financiero..., 50. 


\section{CONCEPTO DE LA DETERMINACIÓN}

Para Gazzerro, la determinación es "la actividad de la administración financiera dirigida a la constatación de la existencia del hecho imponible", y "el procedimiento de recolección, verificación y control de los elementos, datos y circunstancias de hecho que pueden constituir material útil para la motivada determinación del hecho generador y la sucesiva valoración razonada y responsable de tales elementos", así como también "el acto administrativo que concretiza la constatación".

Vanoni dice que es "la fijación de los elementos inciertos de la obligación".

Giuliani define la determinación como "el acto o conjunto de actos emanados de la administración, de los particulares o de ambos coordinadamente, destinados a establecer en cada caso particular la configuración del presupuesto de hecho, la medida de lo imposible y el alcance cuantitativo de la obligación". ${ }^{17}$

Jarach afirma que "la determinación tributaria es un acto jurídico de la administración en el cual esta manifiesta su pretensión, contra determinadas personas, en carácter de contribuyentes o responsables, de obtener el pago de la obligación tributaria sustantiva”.

Para el profesor Sergio Francisco de la Garza, la determinación es un acto del sujeto pasivo por el que reconoce que se ha realizado un hecho generador que le es imputable o un acto de la Administración que constata esa realización, imputable a uno o varios sujetos pasivos, y en ambos casos, por el que se liquida o cuantifica el adeudo en dinero, una vez valorizada la base imponible y aplicada la tasa o alícuota ordenada por la ley.

De este último concepto surge la idea de que la determinación de la obligación tributaria puede ser abordada tanto como un acto jurídico del sujeto pasivo en tanto este sistema funciona bajo el eje de la autodeterminación o autoliquidación o como un acto administrativo fijado por la autoridad tributaria. ${ }^{18}$

La determinación es considerada como un paso ineludible de la obligación tributaria por algunos tratadistas, sobre todo por aquellos que admiten que su autor puede ser el sujeto pasivo.

Giannini explica: "La liquidación del impuesto, en sentido amplio, consiste, precisamente, en el acto o en la serie de actos necesarios para la comprobación y la valoración de los diversos elementos constitutivos de la deuda impositiva (presupuesto material y personal, base imposible), con la consiguiente aplicación de tipo de gravamen y la concreta determinación cuantitativa de la deuda del contribuyente".

17 Carlos Giuliani Fonrouge, Derecho financiero..., 230.

18 Dino Jarach, Finanzas públicas y derecho tributario..., 402. 


\section{NATURALEZA JURÍDICA Y EFECTOS DEL ACTO DE DETERMINACIÓN}

En el Derecho Tributario italiano (con trascendencia al de otros países, como España), se ha producido, desde hace tiempo, sin que hasta la fecha haya concluido definitivamente, un vivo debate, respecto a la conexión que pueda existir entre el nacimiento de la obligación tributaria, por una parte, y los efectos del acto administrativo de liquidación, por la otra.

Para Sainz de Bujanda, el hecho de que el acto liquidatorio sea constitutivo de efectos jurídicos distintos, entre ellos el de la exigibilidad de la deuda, de la constitución en mora, de la apertura de un nuevo plazo de prescripción o de cualesquier otros que el legislador quiera asignar al acto administrativo de liquidación, pudiendo un acto ser mixto, como el mismo Berliri lo reconoce, es decir, a la vez declarativo de una obligación preexistente y constitutivo de otras obligaciones. Parece completamente razonable que "las obligaciones surgidas ex lege no sean exigibles desde luego —es decir, desde que nacen por la realización del presupuesto de hecho previsto en la norma-, si la propia ley que las establece decreta que la exigibilidad sea un efecto jurídico derivado de un ulterior acto administrativo de liquidación o determinación del débito tributario", lo que supone que desde el punto de vista del momento del cumplimiento de la obligación tributaria, "pueden y deben distinguirse dos hipótesis claramente diferenciadas, a saber: $l^{\text {a }}$. Que la obligación sea exigible desde el instante en que nace, esto es, desde el momento en que se produzca el presupuesto de hecho, y $2^{a}$. Que ya surgido el nacimiento, no sea exigible hasta que se produzca el acto liquidatorio. Esta última posibilidad no es solo teórica, sino que encuentra su respaldo constante en los ordenamientos positivos, que con manifiesta reiteración sitúa en momentos distintos el nacimiento de la deuda tributaria y su exigibilidad". ${ }^{19}$

\section{CLASES DE DETERMINACIÓN}

En la mayor parte de las legislaciones extranjeras pueden señalarse varias clases de determinación o liquidación: la liquidación que realiza el sujeto pasivo, directo o por adeudo ajeno según lo determina la ley, cumpliendo un mandato de esta, sin la intervención de la autoridad administrativa; a esta forma de liquidación se le denomina "autodeterminación", y caben otros términos: a) autoliquidación o autoimposición y en contraposición, b) la determinación que realiza la autoridad tributaria en forma autónoma, normalmente en el sistema tributario peruano, mediante el procedimiento de verificación y/o fiscalización; y c) una tercera fórmula, la misma que se realiza en forma conjunta por ambos, lo que en la doctrina se le denomina "concordato".

19 Fernando Sainz de Bujanda, Lecciones de derecho financiero..., 239, 264, 266, 267. 


\section{LA DETERMINACIÓN DE LA OBLIGACIÓN TRIBUTARIA POR EL SUJETO PASIVO}

En la determinación de la obligación tributaria por el sujeto pasivo, este reconoce la existencia de un hecho generador que a él se le atribuye. Mediante la aplicación del parámetro correspondiente, cuantifica en una suma de dinero el importe de su adeudo, lo comunica a la administración tributaria por medio de una declaración y cancela dicho monto en una entidad financiera que oportunamente hubiere suscrito un convenio con la Administración.

Normalmente, si la actividad liquidatoria fue cumplida con exactitud por el sujeto pasivo, el nacimiento, la determinación y la extinción de la obligación tributaria se cumplirán como una actividad exclusiva del sujeto pasivo, sin interferencia alguna del sujeto activo. De no haber procedido con apego a la ley, la autoridad administrativa al revisar la declaración, y al encontrar inadecuación entre ella y las normas legales aplicables, podrá producir un acto rectificatorio, es decir, un acto de determinación por parte de la autoridad tributaria.

Sin embargo, existen algunos autores que niegan el carácter de determinación a dicha actividad liquidatoria del deudor tributario. Jarach, por ejemplo, sostiene que de la naturaleza misma de la determinación resulta "que es una actividad propia de la autoridad administrativa encargada de la tarea de establecer la obligación tributaria", y que "excluimos de la figura de la determinación lo que algunos autores han denominado 'autodeterminación' y otros 'determinación por el sujeto pasivo'”. En el aspecto positivo significa, además, que la determinación solo compete a la administración con o sin la colaboración de los contribuyentes o responsables. ${ }^{20}$

Por su parte, Berliri, después de señalar la "obvia necesidad" de la determinación, agrega que es fácil observar que tal determinación cuando es realizada exclusivamente por el contribuyente "no tiene ninguna relevancia jurídica", ya que es una mera "operación mental" que puede haber sido realizada o no, correcta o incorrectamente, por el contribuyente, y pone el ejemplo del causante del impuesto del timbre, que sin conocer el impuesto que debe pagar simplemente adhiere y cancela los timbres que estima conveniente, de tal suerte que si por casualidad adhirió timbres suficientes no se producirá ninguna consecuencia, ya que "la única cosa que cuenta es el pago del tributo".

Según palabras del profesor De la Garza, debe rechazarse dicha doctrina, en primer lugar, porque la sustancia y los pasos de la determinación son los mismos, ya sea cuando la cumple el sujeto pasivo o la realiza la Administración, y ambas conducen al mismo resultado. En segundo lugar, porque no puede sostenerse que se trate de una mera operación mental sin consecuencias o efectos jurídicos, pues si bien es cierto que no puede haber actos jurídicos en

20 Dino Jarach, Finanzas públicas y derecho tributario..., 410. 
los que no haya intervenido la mente, los resultados de esa operación mental, si no son los previstos u ordenados por la ley, producirán efectos jurídicos para su autor, como recargos, sanciones, etc. Además, es obvio que si la determinación es el cumplimiento de un deber establecido por la ley a cargo del sujeto pasivo, apegándose a instrucciones precisas y detalladas (recuérdese el caso del impuesto al ingreso global de las empresas para los causantes mayores), y que además expresa la pretensión de que sea reconocida en sus elementos por la autoridad destinataria, tiene forzosamente que reconocérsele un carácter jurídico. La determinación efectuada por el sujeto pasivo es definitiva en el sentido de que aplica como acto jurídico, pero sus efectos solamente gozan de presunción relativa de verdad y lo hacen responsable por su contenido, sin perjuicio de su revisión y eventual rectificación por parte de la autoridad administrativa. $^{21}$

\section{LA DETERMINACIÓN: OTRAS FORMAS DE ESTUDIAR LA DETERMINACIÓN POR PARTE DEL OBLIGADO}

\section{Naturaleza jurídica}

La determinación por el obligado es un acto jurídico de reconocimiento de su situación jurídico-tributaria realizado ante la administración tributaria por mandato legal.

\section{Acto jurídico}

a) Es un acto jurídico porque es realizado por un sujeto de derecho consciente y voluntariamente, con miras a producir un resultado eficaz de la consecuencia jurídica.

b) Es un acto de reconocimiento. No se trata de la expresión de un querer del sujeto. No es declaración de voluntad dirigida, en razón de su contenido, a crear, modificar o extinguir una relación jurídica. Es más bien la admisión de una situación jurídica, y, al mismo tiempo, el señalamiento de su contenido.

La pretensión fundamental del acto es manifestar una realidad jurídica. Esa es su esencia. El resultado pretendido por el acto es que tenga por cierta o real la existencia de la situación jurídica en los términos por él señalados.

La situación jurídica objeto del reconocimiento es la que resulta para el obligado a consecuencia de la aplicación del tributo o del goce del beneficio. La determinación tiene lugar siempre a posteriori de la configuración de la situación jurídica. Esta nace de la ley y no es alterada, ni puede serlo, por el reconocimiento. De allí que en caso de divergencia entre la determinación y la situación jurídica subyacente prevalezca esta. La situación jurídica configurada es puesta de manifiesto en el contenido de la determinación. Si el mismo no permite establecer cuál es esa situación jurídica, no existirá la determinación.

21 Francisco de la Garza, Derecho financiero mexicano (México: Porrúa, 1983). 
La determinación no es formulada por el obligado para sí mismo u otros particulares. Se dirige a la administración, que es su destinataria. Es tan esencial este rasgo que sin su comunicación a la Administración, la determinación se considera inexistente; hay que aclarar, sin embargo, que declaración y determinación no son iguales, y que si bien es cierto confluyen, esta puesta en conocimiento es lo que formalmente conceptualizamos como declaración.

Es acto debido, pues se realiza en cumplimiento de un deber jurídico. Este es el rasgo o aspecto más resaltante en su regulación legal. Vale decir, la ley considera más su carácter de deber jurídico (formal) que de acto jurídico. Ello se aprecia en su preocupación por normar el modo y oportunidad de su realización y las consecuencias de su omisión o realización irregular. Siendo acto debido, solo se realiza (o es exigible su realización) cuando la ley lo ordena.

\section{EFECTOS DE LA DETERMINACIÓN}

En general, la descripción de la situación jurídica realizada por el obligado en el acto de la determinación se tiene por cierta provisionalmente (presunción relativa de verdad). Adquiere el carácter de verdad incuestionable si la administración no la modifica mediante resolución firme dentro del plazo de la prescripción (de la acción del fisco para determinar la obligación tributaria, que señala el artículo 44 del Código Tributario).

Específicamente, la determinación por el obligado tiene fuerza vinculante en los supuestos que la ley prevé. Esa vinculación puede operar respecto del propio obligado como de la Administración, según los casos:

- Tiene fuerza vinculante para el sujeto en tanto se determine una obligación a su cargo vencida y pendiente de pago.

Se desprende ello del artículo 78, inciso 1 del Código Tributario, el cual autoriza a la Administración a exigir (mediante la emisión de la orden de pago) el pago del tributo autoliquidado.

- Tiene fuerza vinculante para la Administración en diversos supuestos. Por ejemplo:

- Cuando se determinan pagos en exceso por tributos sujetos a pagos a cuenta, pudiendo el pago en exceso compensarse con obligaciones futuras correspondientes al mismo tributo: Ej.: Impuesto a la Renta: D. Leg. 774, artículo 87.

- Cuando se determinan pérdidas arrastrables. D. Leg. 774, artículo 53.

- Cuando se determina un crédito fiscal arrastrable (saldo a favor) para fines del I.G.V. D. Leg. 821, artículo 25. 
En todos los casos, los efectos se producen por ministerio de la ley y no en razón de la voluntad del sujeto. La modificación de la declaración propuesta por el administrado u obligado tiene plena vigencia y goza de absoluta eficacia jurídica, siempre y cuando no sea modificada por la determinación firme de la Administración, de acuerdo al artículo 61 del Código Tributario, o no sea objeto de sustitución o rectificación por el propio sujeto a la luz del artículo 88 del Código Tributario.

Cuando el acto no produce efectos vinculantes como los señalados, no tiene otro resultado práctico que el de poner a la Administración en posición de poder ejecutar su facultad de fiscalización a partir de la información proporcionada. ${ }^{22}$

\section{LA DETERMINACIÓN COMO ACTO JURÍDICO}

¿Qué es la determinación regulada en el Código Tributario?

Constituye un acto jurídico, ya que contiene los elementos establecidos en el artículo 140 del Código Civil referidos al acto jurídico; además se infiere que la determinación es el acto jurídico por el que se declara la existencia y cuantía de la obligación tributaria a cargo del contribuyente.

Sin embargo, existen situaciones en que la determinación no tiene objetivo, al establecer la existencia y cuantía de la obligación tributaria, como por ejemplo:

Si la determinación tiene lugar por el obligado:

a) La declaración de patrimonio o ingresos exonerados.

b) La declaración de pérdidas.

c) La declaración de renta neta sin liquidación del impuesto, por no ser sujeto contribuyente.

d) La declaración sin cálculo alguno por no haber realizado operaciones.

22 Texto Único Ordenado del Código Tributario. Artículo 1: "La obligación tributaria, que es de derecho público, es el vínculo entre el acreedor y el deudor tributario, establecido por ley, que tiene por objeto el cumplimiento de la prestación tributaria, siendo exigible coactivamente".

Artículo 2: "La obligación tributaria nace cuando se realiza el hecho previsto en la ley, como generador de dicha obligación".

Artículo 3: "Cuando deba ser determinada por el deudor tributario, desde el día siguiente al vencimiento del plazo fijado por ley o reglamento y, a falta de este plazo, a partir del decimosexto día del mes siguiente al nacimiento de la obligación". 
Los ejemplos señalados en los puntos a) al d) nos acercan más a una declaración que a una propia determinación de la obligación tributaria.

Si la determinación tiene lugar por la Administración, el acto por el que simplemente se establece la existencia de una materia imponible sin determinación de la obligación:

e) La determinación practicada a entidades que no son sujetos del impuesto a la renta según el artículo 14, último párrafo del D. Legislativo 774.

f) El acto por el que se formulan reparos a la declaración de pérdidas, disminuyéndolas.

g) El acto por el que se ajusta el crédito fiscal arrastable para fines del IGV.

\section{LA DETERMINACIÓN POR LA ADMINISTRACIÓN}

Como es de conocimiento general, el Texto Único Ordenado (TUO) del Código Tributario en su artículo 59 establece que, por el acto de determinación de la obligación tributaria, no solo el deudor sino también la Administración Tributaria ostentan la facultad de verificar la realización del hecho generador de la obligación tributaria, identificar al deudor tributario, así como la cuantía del tributo.

\section{NATURALEZA JURÍDICA}

La determinación por la Administración tiene la naturaleza de acto administrativo. Cuando no determina una obligación tributaria, el acto solo expresa el juicio de la Administración sobre la situación jurídica del sujeto al cual se refiere. Cuando declara la existencia y cuantía de la obligación, la expresión de ese juicio puede ir acompañada de una exigencia de pago, que ya es una manifestación de voluntad de la administración.

La situación jurídica objeto de la declaración es la configurada respecto del sujeto con aplicación del tributo o del goce del beneficio tributario.

XVIII. EFECTOS DE LA DETERMINACIÓN DE LA OBLIGACIÓN TRIBUTARIA POR PARTE DE LA ADMINISTRACIÓN TRIBUTARIA

El efecto propio de la determinación administrativa, una vez firme, es definir la situación jurídica del sujeto respecto del tributo y, en su caso, periodos considerados. Ocurrido ello, las consecuencias legales inherentes a esa situación se considerarán retroactivamente producidas desde el momento prefijado en la ley.

También hay que considerar que la determinación por parte de la Administración produce efectos desde su notificación: 
- Interrumpe el plazo de prescripción (Código Tributario, artículo 45, inciso a).

- Coloca a la Administración en la posibilidad de adoptar medidas cautelares cuando señala la existencia de una obligación (Código Tributario, artículo 56).

- Coloca al obligado en la necesidad de impugnarla en el plazo de ley, teniendo en cuenta que es un acto administrativo, y, por tanto, tiene el carácter de impugnable, si es que pretende desvirtuar su ejecución, sea o no que establezca la existencia de una obligación (artículo 135 del Código Tributario).

\section{CONDICIONES DE VALIDEZ}

El Código Tributario no señala expresamente cuáles son las condiciones de validez del acto de determinación por la Administración Tributaria. Sin embargo, la doctrina ha tratado de explicar las propias condiciones para su plena eficacia jurídica dentro de la relación jurídicotributaria.

\section{a) Fiscalización previa}

La fiscalización es el proceso de investigación realizada por la Administración tendente a determinar la situación jurídica de un sujeto a consecuencia de la aplicación de un tributo o del goce de un beneficio. Lógicamente implica un requerimiento hecho al sujeto para que proporcione la información o exhiba la documentación a ser fiscalizada; la realización de los exámenes, pesquisas, verificaciones y evaluaciones correspondientes, y, de ser el caso, la emisión y notificación del acto de determinación. En materia de tributos internos, no existe un procedimiento riguroso respecto al acto de fiscalización previa. Situación diferente se advierte, por ejemplo, en el tema aduanero, donde los procedimientos están encapsulados por su extremada rigidez. Esta diferencia hace que la facultad discrecional del fiscalizador llámese auditor-, quien representa funcionalmente a la Administración Tributaria, fije un criterio discrecional al momento de realizar los actos de fiscalización previa. ${ }^{23}$

\section{b) Fiscalización o verificación de la determinación realizada por el deudor tributario}

Según palabras de Sáenz Rabanal, la determinación por el deudor tributario se encuentra sujeta a la verificación por parte de la Administración, a través de los conocidos procesos de fiscalización, de modo que su certeza se ve materializada firmemente luego de la intervención fiscal. ${ }^{24}$

23 César Talledo Mazu, "La determinación como acto jurídico", Cuadernos Tributarios, № 23 (junio 1999).

24 María Sáenz Rabanal, "Facultades de la administración en materia de determinación de tributos", Revista del Instituto Peruano de Derecho Tributario, Nº 30 (1997). 
Sáenz opina que "la determinación vía declaración efectuada por el propio deudor tributario no goza de presunción absoluta de verdad, ya que dicha determinación contenida en la declaración puede ser desestimada por la Administración, cuando esta dude de la misma; ello ocurre en general cuando por una razón u otra la Administración a través de los procesos de fiscalización, facultad de que goza, advierte de una declaración falsa o incompleta proporcionada por el deudor en una autoliquidación, procediendo a su rectificación vía determinación, la misma que es practicada por la propia Administración y a través de un acto administrativo que emite la misma (resolución de determinación)".

Folco afirma que una función fundamental de la Administración Tributaria es la actividad de comprobación, y, citando a Vicente Díaz, refiere que las tres reglas básicas de su sustento son: a) la veracidad y el propio tiempo en que se efectuó la declaración tributaria; b) el conjunto de documentación que la sustenta; c) la correcta determinación del impuesto. ${ }^{25}$

Según Gonzales y Lejeune, "a la hora de aplicar los tributos, y ya se apliquen estos a través del sistema tradicional (declaración, comprobación, liquidación) o del esquema actualmente generalizado consistente en la autoliquidación por el propio sujeto pasivo, la comprobación administrativa ocupa un lugar primordial: se trata en ese momento, de dejar perfectamente definidos, tras su verificación, los hechos imponibles efectivamente realizados, cuantificada la dimensión económica de los mismos, es decir, la base imponible, y, por último, determinada la deuda tributaria, bien confirmando la autoliquidada por el sujeto pasivo, bien la que a juicio de la Administración resulte correcta de acuerdo con las normas reguladoras del tributo y los elementos probatorios de que disponga. Es en esta función de comprobación a realizar por la Administración, donde encaja la actividad que desarrollan los órganos de la inspección. ${ }^{26}$

En palabras del Dr. Rosendo Huamani Cueva, citando la RTF No 7669-1-2004, la determinación efectuada por el deudor tributario estando sujeta a verificación o fiscalización por parte de la Administración Tributaria puede ser modificada por esta cuando constate la omisión o inexactitud en la información proporcionada, emitiendo la resolución de determinación, orden de pago o resolución de multa.

\section{DETERMINACIÓN DE LA OBLIGACIÓN TRIBUTARIA}

De acuerdo a lo establecido por el Código Tributario en su artículo 59 sobre determinación de la obligación tributaria:

a) El deudor tributario verifica la realización del hecho generador de la obligación tributaria, señala la base imponible y la cuantía del tributo.

25 Carlos M. Folco, Procedimiento tributario (Buenos Aires: Rubinzal Culzoni, 2000).

26 Eusebio Gonzales y Ernesto Lejeune, Derecho tributario, tomo 1 (Salamanca: Plaza Universitaria Ediciones, 1997). 
b) La Administración Tributaria verifica la realización del hecho generador de la obligación tributaria, identifica al deudor tributario, señala la base imponible y la cuantía del tributo. ${ }^{27}$

Queda claro que la determinación de la deuda tributaria es un procedimiento que debe ser efectuado por el propio deudor tributario, la Administración y ambos en forma conjunta; aunque esto último no aparece en forma taxativa, pero sí aplicable, principalmente en el tema de los tributos aduaneros.

En esa posición, está plenamente establecido que la acción por la que el deudor tributario establece la determinación de la obligación se considera una parte consustancial de la propia delimitación de la deuda tributaria, y es que resulta importante señalar que no puede hablarse de deuda en general o deuda tributaria en particular, si esta no ha sido absolutamente determinada mediante un procedimiento establecido en la propia ley; además, hay que decir que la determinación de la obligación tributaria, cuando es realizada por el deudor, es denominada en la doctrina autoliquidación o autodeterminación, esto es, que el sistema imperante que asume nuestra legislación acepta la autoliquidación más por razones de costos y logística que por razones de favorecer al propio contribuyente, aunque con la limitación de que dicha determinación vía declaración únicamente goza de presunción relativa de verdad, la misma que puede ser sujeta a su modificación, cuando por razones jurídicamente valederas la propia Administración justifique que no se ajusta a la verdadera dimensión de la determinación, o en un estado extremo se compruebe que adolece de veracidad.

La posibilidad de que el propio deudor tributario proceda a la determinación de la obligación tributaria resulta razonable, ya que no podemos imputar toda acción de la determinación a la Administración, pues se parte de una trascendencia que afectaría el propio sistema de recaudación, toda vez que la Administración no se encuentra razonablemente apta para proceder a efectuar la determinación de miles o millones de contribuyentes. Por obvias razones, no todos los sistemas tributarios podrían adoptar el sistema de autoliquidación, aunque en la mayoría resulta ser la regla general. Por las razones ya expuestas y por otras que se manejan en la doctrina, sí es verdad, en cambio, que, aunque se aplique un sistema de autoliquidación, no se deja en inacción a la Administración Tributaria, ya que esta no pierde facultades, sino que en el fondo las delega. No nos estamos refiriendo a la potestad tributaria delegada, sino únicamente a lo que resulta de la propia determinación de la obligación tributaria, siguiendo la Administración Tributaria el mismo camino que le corresponde por la propia ley, cual es el de verificar y controlar que dicha liquidación sea de forma correcta e impoluta, utilizando para ello las facultades discrecionales de la que goza la Administración, como la verificación y/o fiscalización.

27 Texto Único Ordenado del Código Tributario. Artículo 59. 
En palabras del Dr. Huamani, una vez materializada en la realidad la hipótesis de incidencia tributaria, nace la obligación tributaria, y para ser exigible esta se hace necesaria su determinación. ${ }^{28}$

Soler explica la determinación de la obligación tributaria de la forma siguiente: "La determinación tributaria es el acto por el cual se llega a establecer la existencia de una deuda tributaria, se individualiza al obligado a pagarla y se fija el importe de la misma". ${ }^{29}$

Giuliani sostiene que "la determinación de la obligación tributaria consiste en el acto o conjunto de actos emanados de la Administración, de los particulares o de ambos coordinadamente, destinados a establecer en cada caso particular, la configuración del presupuesto de hecho, la medida de lo imponible y el alcance de la obligación". ${ }^{30}$

En palabras de Grellaud, "la determinación es considerada como el acto o conjunto de actos dirigidos a precisar si efectivamente se realizó el hecho previsto en la ley como hipótesis de incidencia, y a cuantificar la obligación tributaria, convirtiéndola en exigible". ${ }^{31}$

Por otro lado, Talledo expone el siguiente concepto sobre la determinación: "La determinación es el acto por el que se define (...) la situación jurídica de un sujeto a consecuencia de la aplicación del tributo o goce de un beneficio". ${ }^{32}$

Siguiendo el sentido de lo anotado por el Dr. Huamani, el acto de "determinación" tiene el carácter de simple acto declarativo del nacimiento de la obligación tributaria". ${ }^{33}$

Como sostiene Villegas, "si bien es cierto que la determinación no hace nacer la obligación tributaria, brinda eficacia a una obligación que existía solo potencialmente desde la configuración del hecho imponible; es decir, el verdadero efecto de la determinación es el de ratificar que cuando se produce el hecho imponible nace realmente la obligación tributaria". 34

Por ello, afirma García que con la determinación se "crea un estado de certeza sobre la existencia y el alcance de la obligación tributaria preexistente. Ratifica que se produjo el hecho imponible, que no se configuraron hipótesis neutralizantes totales, la medida de la deuda, que esta no se extinguió, etc.”. ${ }^{35}$

\footnotetext{
28 Rosendo Huamaní Cueva, Código Tributario comentado (Lima: Juristas Editores, 2009).

29 Osvaldo Soler, Derecho tributario..., 241.

30 Carlos Giuliani Fonrouge, Derecho financiero..., 501.

31 Guillermo Grellaud Guzmán, "Facultades de la Administración en materia de determinación de tributos", Revista del Instituto Peruano de Derecho Tributario, No 30 (1997).

32 César Talledo Mazu, "La determinación como acto jurídico", Cuadernos Tributarios, № 23 (junio 1999).

33 Rosendo Huamaní Cueva, Código Tributario comentado (Lima: Juristas Editores, 2009).

34 Héctor Villegas, Curso de finanzas, derecho financiero y tributario..., 400-401.

35 Catalina García Vizcaíno, Derecho tributario, tomo 2 (Buenos Aires: Depalma, 1997).
} 
El mismo Villegas concluye "que según la solución que se acepta (carácter declarativo de la determinación), no cabe duda de que las circunstancias de hecho a tener en cuenta y la ley que regulará el caso serán aquellas existentes al momento de producirse el hecho imponible". ${ }^{36}$

Como señalan Chau y Lozano, a través de la determinación se logra establecer en forma concreta la deuda tributaria; "ya que si bien la obligación tributaria se considera nacida en el momento en que la hipótesis de incidencia prevista por el legislador acaece en la realidad, la determinación — sin perder su carácter declarativo- permite precisar tal suceso, cuantificándola". ${ }^{37}$

La autoliquidación es la facultad de la que goza el propio administrado a fin de que él mismo proceda a identificar el hecho imponible, así como a los sujetos que participan en la relación jurídica tributaria, es decir, tanto al sujeto pasivo de la obligación tributaria como al sujeto activo, establecer la base de lo imponible o la base de cálculo, la alícuota legal y, por último, la porción dineraria del tributo a cancelar; según Lago Montero, son "aquellos actos administrativos que se pronuncian sobre la existencia y la cuantía de una obligación tributaria originada por la realización del hecho imponible".$^{38}$

Por otro lado, como lo expone Ángel Augusto Vivanco Ortiz, la autoliquidación vendría a ser un acto unilateral por medio del cual el deudor tributario pone en conocimiento de la Administración la deuda tributaria que tiene con el fisco y los conceptos de los mismos.

Habría que aclarar que normalmente la determinación de la obligación tributaria va encerrada dentro de lo que se denomina la declaración, pero entiéndase que determinación y declaración tienen sus propias definiciones conceptuales, aunque en la práctica tributaria estas diferencias pasen inadvertidas.

Según lo indicado por el autor de los párrafos precedentes, el deudor tributario asume de manera preliminar que tiene obligaciones hacia el fisco, o que no las tiene. Si manifiesta tener obligaciones está reconociendo que debe y que lo que corresponde es honrar dichas deudas, bajo apercibimiento de que la Administración Tributaria despliegue el poder de coacción y de coerción a fin de hacerse del pago de dichas acreencias, esto en virtud de la potestad tributaria de la que goza; pudiendo en algunos casos ejercer tal presión contra el sujeto pasivo pese a la férrea resistencia que este pueda oponer.

36 Héctor Villegas, Curso de finanzas, derecho financiero y tributario..., 250.

37 Lourdes Chau Quispe y Oswaldo Lozano Byrne, "La determinación sobre base presunta: un punto de vista jurisprudencial”, Themis, Revista de Derecho, publicación editada por alumnos de la Facultad de Derecho de la Pontificia Universidad Católica del Perú, Nº 41 (2000).

38 José Lago Montero, La suspensión de liquidaciones tributarias en la reposición y en la vía económico-administrativa (Madrid: Tecnos, 1993). 


\section{LA DECLARACIÓN. CONCEPTO Y NATURALEZA JURÍDICA}

Berliri escribe que puesto que puede resultar sumamente difícil para la Administración Tributaria conocer la realización de los hechos generadores que en forma múltiple pueden producirse sin su conocimiento, "es lógico que la ley imponga, sea al deudor del tributo, y en algunas circunstancias a terceros, más o menos relacionados con aquel, la obligación de informar a la Administración de la realización del presupuesto de hecho, de la entidad de la base imponible, así como de todos los otros elementos necesarios o simplemente útiles para la aplicación del tributo, y de comunicarle todos aquellos hechos y circunstancias que puedan consentirle un más eficaz desarrollo de su función determinadora”.

Como lo expresa el Código Tributario, existen dos formas de determinación de la obligación tributaria: por el deudor tributario y por la Administración.

Para Vanoni, la declaración es "la comunicación, realizada por el sujeto a quien obliga la ley, a la Administración Tributaria, de haberse realizado el presupuesto y los elementos idóneos para fijar en concreto la prestación debida". Según Jarach, "es un acto que manifiesta el saber y la voluntad de cumplir una obligación, sin eficacia definitoria de la obligación sustancial". 39

Gazzerro la define como "el acto por el cual el contribuyente debe cumplir la obligación de determinar las rentas sujetas a impuesto mediante los datos y los elementos relativos a los hechos y a la situación que constituyen el presupuesto de la obligación tributaria”.

\section{CONCLUSIONES}

1. La justificación del derecho reside en la solución de situación o relaciones jurídicas existentes en el tiempo; estas relaciones para su mejor estudio y presentación han sido divididas de aquellas provenientes de las relaciones jurídicas públicas y privadas.

2. En el desarrollo del trabajo se ha tenido en cuenta principalmente el vínculo de aquellas relaciones jurídicas sustentadas en que ellas generan obligaciones por razones del vínculo de sujetos de derecho, uno de los cuales debe cumplir con una prestación determinada al cual está vinculado por alguna razón ya sea porque se ha desarrollado un hecho previsto en la ley como generador de dicha obligación o en el desarrollo de la autonomía de la voluntad privada; en este último caso, siempre con el límite de orden público interno y ley imperativa.

3. Se ha aproximado la idea de que dicho vínculo genera una serie de compromisos por parte de un sujeto en dicha relación jurídica que debe recaer en el sujeto pasivo de la obligación, el mismo que tiene que satisfacer mediante el pago generalmente u otra prestación prevista con antelación.

39 Dino Jarach, Finanzas públicas y derecho tributario..., 203. 
4. He tratado de realizar el trabajo aplicando un razonamiento lógico jurídico a través del uso de conceptos abstractos: hipótesis de incidencia y la propia configuración de dicha hipótesis aplicada a un hecho en particular que lo haga generador de dicha obligación.

5. Se ha llevado a cabo el esfuerzo de trascender el concepto de la obligación en el ámbito civil y verificar que dicho concepto tiene un carácter transversal en el derecho; utilizando el acercamiento al derecho civil (derecho alimentario), el propio derecho civil (derecho de las obligaciones) y finalmente en el campo de estudio del derecho tributario.

6. Se ha destacado que el método para establecer la obligación, es decir, este vínculo que une a un sujeto frente a otro, no puede ser eficaz y exigible si no se parte de un procedimiento establecido en la ley o en el establecimiento de acuerdos fijos en el ámbito privado (contractual); este aspecto lo constituye la determinación de dicha obligación, el cual tiene como fase una serie de criterios y procedimientos para su validez en el sistema jurídico de las obligaciones.

7. Se ha pretendido establecer que en el ámbito del derecho tributario solo se puede establecer con precisión un adeudo cuando este se encuentre debidamente delimitado, es decir, que exista un conocimiento pleno del quantum de dicha obligación.

\section{REFERENCIAS}

- Ataliba, Geraldo. Hipótesis de incidencia tributaria. Lima: Instituto Peruano de Derecho Tributario, 1987.

- Bravo Cucci, Jorge. Fundamentos de derecho tributario. Lima: Palestra Editores, 2003.

- Celis, Marco. "La inconstitucionalidad de la Ley 29486" (artículo jurídico, 2011).

- Chau Quispe, Lourdes y Oswaldo Lozano Byrne. "La determinación sobre base presunta: un punto de vista jurisprudencial". Themis, Revista de Derecho, publicación editada por alumnos de la Facultad de Derecho de la Pontificia Universidad Católica del Perú, N ${ }^{\circ} 41$ (2000).

- De la Garza, Francisco. Derecho financiero mexicano. México: Porrúa, 1983.

- Folco, Carlos M. Procedimiento tributario. Buenos Aires: Rubinzal Culzoni, 2000.

- García Vizcaíno, Catalina. Derecho tributario. Tomo 2. Buenos Aires: Depalma, 1997.

- Giuliani Fonrouge, Carlos. Derecho financiero. Tomo I. Buenos Aires: Ediciones Depalma, 2001. 
- Grellaud Guzmán, Guillermo. "Facultades de la Administración en materia de determinación de tributos". Revista del Instituto Peruano de Derecho Tributario, $\mathrm{N}^{\circ} 30$ (1997).

- Huamaní Cueva, Rosendo. Código Tributario comentado. Lima: Juristas Editores, 2009.

- Gonzales, Eusebio y Ernesto Lejeune. Derecho tributario. Tomo 1. Salamanca: Plaza Universitaria Ediciones, 1997.

- Jarach, Dino. Finanzas públicas y derecho tributario. Estudios de derecho tributario. Buenos Aires: Cima, 1996.

- Lago Montero, José. La suspensión de liquidaciones tributarias en la reposición y en la vía económico-administrativa. Madrid: Tecnos, 1993.

- Osterling Parodi, Felipe y Mario Castillo Freyre. Tratado de las obligaciones. Vol. XVI, tomo 1. Lima: Pontifica Universidad Católica del Perú, 1994.

- Pérez de Ayala, José. "La subjetividad tributaria”. En Tratado de derecho tributario. Tomo segundo. Bogotá: Temis, 2001.

- Sáenz Rabanal, María. "Facultades de la administración en materia de determinación de tributos". Revista del Instituto Peruano de Derecho Tributario, № 30 (1997).

- Sainz de Bujanda, Fernando. Lecciones de derecho financiero. Madrid: Universidad Complutense, Facultad de Derecho, 1993.

- Soler, Osvaldo. Derecho tributario. Buenos Aires: La Ley, 2002.

- Talledo Mazu, César. "La determinación como acto jurídico". Cuadernos Tributarios, $\mathrm{N}^{\circ}$ 23 (junio 1999).

- Villegas, Héctor. Curso de finanzas, derecho financiero y tributario. Buenos Aires: Astrea, 2002 . 


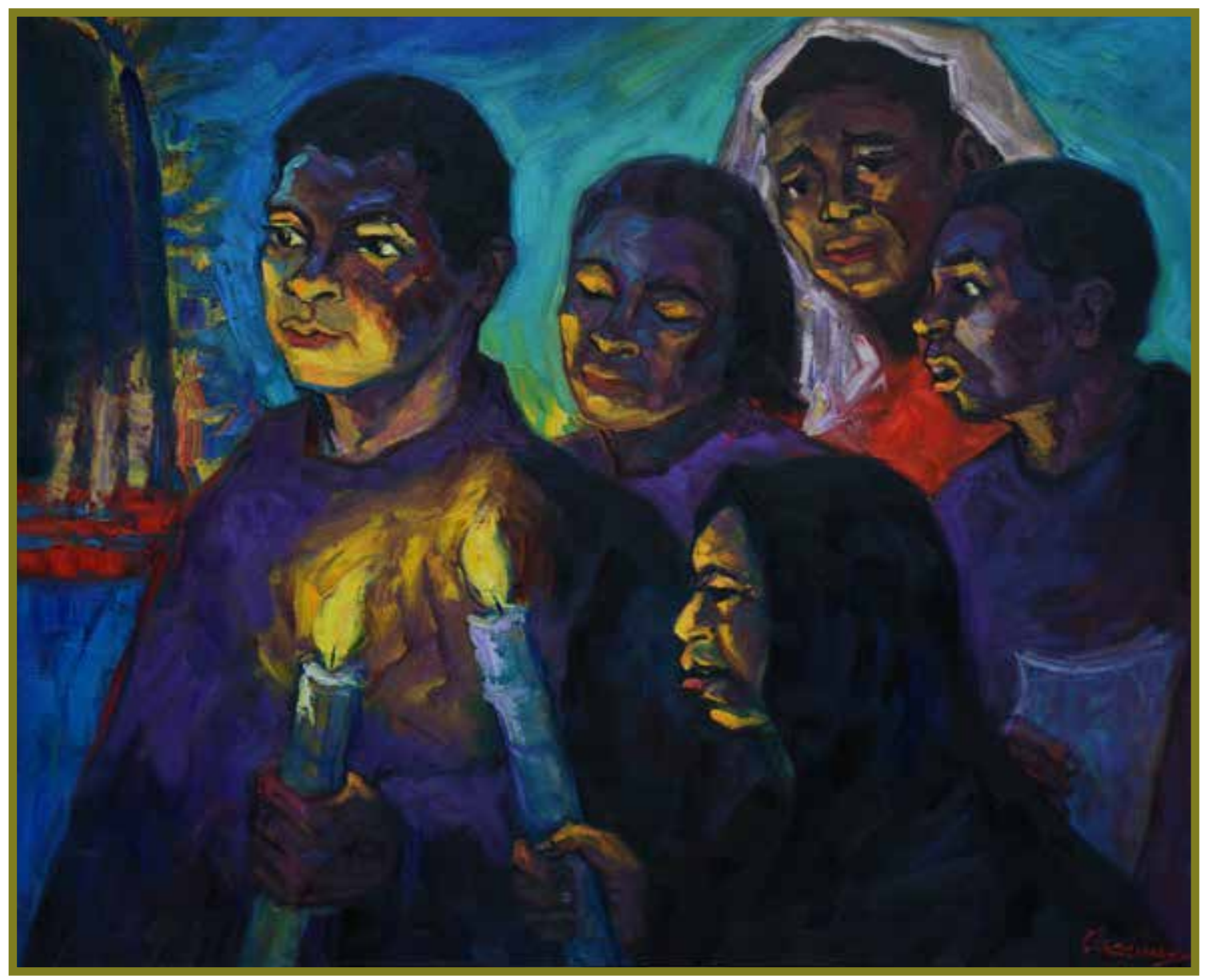

Fe en luz. Óleo sobre lienzo $(90 \mathrm{~cm}$ x $110 \mathrm{~cm})$. Ever Arrascue. 